\title{
Productivity Enhancement with Material Handling System Design and Human Factors Analysis - a Case Study
}

\author{
Muhammad Waseem ${ }^{1 \mathrm{a}}$, Usman Ghani ${ }^{2}$, Tufail Habib ${ }^{1 \mathrm{~b}}$, Sahar Noor ${ }^{1 \mathrm{c}}$, $_{\text {Tauseef }}{ }^{1 \mathrm{~d}}$
}

RECEIVED ON 15.05.2019, ACCEPTED ON 03.03.2020

\begin{abstract}
Global competitiveness leads industry to meet the customer needs by short lead time to market and quality products with low prices. Survival in such a market can be accomplished by either adopting latest technologies or improving the existing systems to the best possible level. Acquiring these technologies need heavy investments and consistent demands due to which small and medium industries skip this option and tend to opt for other choice that is: improve the existing system. Material handling activities contributes a significant investment in production cost. Effective handling system reduces total production cost while considering ergonomics issues improves the productivity. This paper presents a conceptual framework with material handling systems design and the effects of human factors to improve productivity by reducing cost and optimizing quality. The framework provides a general methodology for analyzing a manufacturing/production line. Procedure for its implementation is discussed in a hierarchical way and finally the framework is used to analyze the production lines of a petrochemical industry. The analysis results in successful improvement of the process with $15 \%$ increase in overall manufacturing cycle efficiency.
\end{abstract}

Keywords: Productivity, Material Handling, System Integration, Human Resource, Efficiency

\section{INTRODUCTION}

I n today's modern world, Material Handling Equipment (MHE) has been playing an important role in the improvement of industries' productivity. Huge investment is required to establish an advanced and well developed MHE system. It not only requires money but also needs suitable personnel which can install and manage properly. However, this amount is recovered in terms of increasing productivity, therefore proper MHE should be selected because it comprises $30-40 \%$ of the total production cost [1]. Type and place of MHE represents major challenges for engineers and managers while deciding MHE. Applications of MHE are not just limited to the manufacturing firms but its usage areas also include shipping and receiving, fabrication, warehousing and assembly etc. Complexity of MHE selection is contributed by different factors that are imposed by the environment, materials and facilities etc. [2].

Additional factor that restrict many small and medium scale industries from installing these latest MHE is its high prices therefore these industries rely on traditional MHE. Traditional MHE usually depends on the workers therefore productivity is impacted when the workers are not properly trained. These workers must handle the equipment in an ergonomic way to improve productivity while considering health issues. Ergonomics is usually ignored at managerial level and is not considered as an effective tool of improvement. However, it is related to health issues [3]. The definition of ergonomics depict that it not only considers physical aspects but it also considers social,

${ }^{1}$ Department of Industrial Engineering, University of Engineering and Technology Peshawar, Pakistan.

amwaseem@uetpeshawar.edu.pk, btufailh@uetpeshawar.edu.pk, ${ }^{\mathrm{c}}$ sahar@uetpeshawar.edu.pk,

duetian246@gmail.com

${ }^{2}$ Department of Mechanical Engineering, University of Engineering and Technology Peshawar, Pakistan.

Email: usmanghani@uetpeshawar.edu.pk

This is an open access article published by Mehran University of Engineering and Technology, Jamshoro under CC BY 4.0 International License. 
economic and psychological aspects. Additionally, ergonomics helps to solve technical as well as organizational issues. In short, it improves the overall system performance. Production flexibility, quality levels, lead time, desired output and cost are considered as some of the systems performance. Most of the time, managers try to improve the company productivity by adopting lean manufacturing practices rather than ergonomics approach $[2,4]$.

Human intervention cannot be ignored even if the industries adopt latest types of MHE as these technologies are still dependent on humans. Therefore the interaction between human and machine should be properly considered. One cannot just rely on the latest tools of the systems like Computer Integrated Manufacturing (CIM). These tools are still operated by humans whose contribution should not be neglected [5]. To improve the efficiency of manufacturing firms, researchers have developed different methods and techniques to analyze system design, ranging from micro level study e.g. individual tasks to macro level study at organizations level [6].

The objective of this study is to establish a research paradigm whereby MHE design and ergonomics can be integrated to achieve optimum productivity. This paradigm is aimed at providing a framework for proximate application of the results in industry. Further, this paper analyzes the system performance at macro-level. It also explains the effect of effective MHE design and human factor on the overall efficiency of the system. The framework developed in this paper is applied to a case study, presented in next sections that shows the relationship between factors affecting the human performance and productivity. Two types of audience are targeted in this paper:

- It represents the importance of human factors and ergonomics to engineering managers and manufacturing engineers that humans can improve the productivity rather than reduce it.

- It represents the basic problems and challenges where the ergonomics can help. It targets the ergonomists to demonstrate proper methods for such situation to improve the efficiency.

Ergonomists must know about the systems like production volume, production rate, product design etc. to develop suitable postures in accordance otherwise there will be no effect on the productivity.

\section{LITERATURE REVIEW}

A number of authors have developed different models and methods for selection of material handling for a new facility or an existing facility but there is lacking in research regarding the improvement of existing $\mathrm{MHE}$ as it is not always feasible for an organization to move towards replacement of MHE [7].

Welgama and Gibson [8] categorized layout and material handling system problems into three approaches: layout is given, handling approaches are given, and neither is given [8-10].

Palliyil [11] developed a procedure to design a material handling layout on the basis of block layout. Some researchers have tried to integrate material handling system and facility layout. Don Taylor studied the relation of material handling systems with facility layout $[12,13]$.

Peters et al. [14] developed a solution that solves the MH system design issues in flexible manufacturing systems with flow paths having simple loops.

The cost of material handling in facilities design is an important factor whether it is for the new facility or for the redesign of an existing facility. Handling activities generally account for 30-40 percent of production cost [1]. Therefore, well-designed $\mathrm{MH}$ systems are crucial for reduced costs and increased profits. Large scale industries tend towards automation of their material handling activities. However small and medium scale firms rely on individual experience.

Askin et al. [15], presented models that integrate layout design, capacity planning and process selection in the context of cellular manufacturing systems.

\section{FRAMEWORK AND RESEARCH METHODOLOGY}

Fig. 1 indicates the methodology to a standard material handling system. This framework enables to 
understand the existing material handling system and devise a new method to handle the material in an effective way.
This framework helps the firms to analyze their existing system and identify the deficiencies to overcome. It comprises of the following steps:

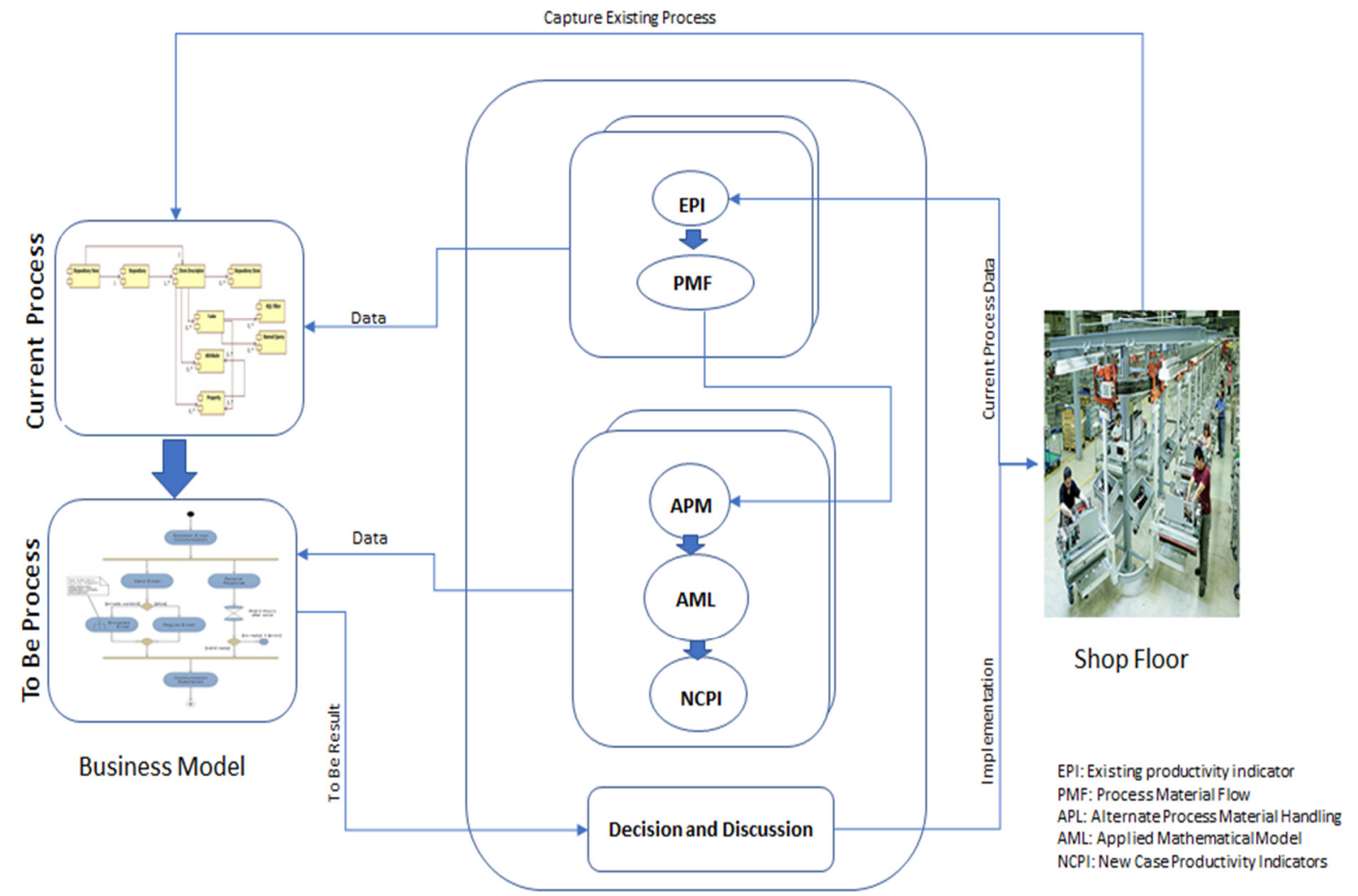

Data Model

Fig. 1: Framework and research methodology

\subsection{Data Model}

Data model consists of existing data indicator, process material flow, alternate process material handling, applied mathematical models and new case productivity indicators. Detail of each model is presented as below.

\subsubsection{Existing Productivity Indicator}

Prior to the modification of the system, it is necessary to analyze the existing process in terms of productivity. Productivity is commonly defined as a ratio of a volume measure of output to a volume measure of input use.

Productivity measures at industry levels are computed for different activities. These include the following:
- Labor input

- Labor productivity

- Contributions to labor productivity growth

- Unit labor costs and their components

\subsubsection{Process Material Flow}

After identifying the existing productivity level, next is model material flow. Any production/manufacturing unit starts from some sort of raw material and ends at a desired finished product. This raw material flows through a number of processing steps to change into the finished product. At this level, these steps are to be analyzed both theoretically and practically to identify the gap.

The objective is easily understood: Minimize transport, storage, and handling costs, reduce 
investment and floor space requirements, produce well-structured processes and identify areas of responsibility, a high level of resistance to failure, a reduction in headcount and a flexible reaction to fluctuating business volumes and much more... Thus, we require an efficient and economically viable system which will meet current and future demands which work unobtrusively in the background and does not incur unnecessary recurring and one-off costs. The procedure to improve the flow of material can be roughly classified into four steps

- Preliminary work to the identification of data

- Operations planning to find concepts

- Detailed planning

- Realization and implementation of the system

\subsubsection{Alternate Process Material Handling:}

The product through a process flows with the help of material handling equipment. Selection of suitable material handling equipment (MHE) is a very difficult task for the manufacturing companies because of the considerable capital investment required. There are many tangible and intangible factors for choosing suitable MHE [1, 16].

MH systems integrate individual handling machines to develop a whole system. [17, 18]. MH system varies depending upon its applications, system elements and physical scale [19]. While planning $\mathrm{MH}$ systems, proper handling procedures are determined to achieve the desired goals. Researchers have developed two solutions for this task; task-based and system-based approach. The first one analyzes individual tasks while the second one considers the whole system for analysis [20].

\subsubsection{Applied Mathematical Models}

Selection of appropriate material handling equipment is followed by a defined mathematical model. These models are used to identify an optimum set of equipment and the manner in which this equipment should be used. Mathematical modeling also helps us to find the efficiency of each equipment that helps in taking further decision for improvement.

\subsubsection{New case productivity indicators}

Having analyzed existing productivity and material flows, alternate material handling equipment are identified. Using mathematical modelling, efficiency of these equipment is found. At this stage, after changes are introduced in the system. Productivity is measured for the updated system as done for existing system.

\subsubsection{Decision and discussion:}

It is the last step in the framework. After the whole system is analyzed and implemented before and after the modifications, it helps the decision makers to take the practical step and implement the suggestions to achieve the results.

\section{SHOP FLOOR}

Shop floor of the existing system is analyzed and a layout is developed. Depicting the existing layout helps the decision maker what to change and where to change.

\section{BUSINESS MODEL:}

\subsection{Current process:}

After completing the abovementioned steps, overall process of the existing system is captured. A process model is prepared to identify the bottleneck and the point where changes could be made for improvement. Further, it shows us the real time data of the whole process. Although providing exact data in the input is also a tedious task but it still generates better results and provide places for improvement.

\subsection{To be process:}

Modifications suggested in the above steps are introduced here. New business process model of the whole system is developed included the changes. It helps the manufacturers visualize the improvements and take decisions appropriately.

\section{CASE DESCRIPTION}

Dynea Pakistan Limited (the Company) is engaged in 
the manufacturing and sale of formaldehyde, molding compound powder, and urea/melamine formaldehyde and aminoplast compound. The major raw materials include:

- Urea: Each bag weighing $50 \mathrm{~kg}$

- Cellulose: Each lot weighing $250 \mathrm{~kg}$

- Hexamethylenetetramine: Each bag weighing $25 \mathrm{~kg}$

- Sea salt: Each bag having an average weight of $20 \mathrm{~kg}$ but it varies

- Melamine: Each bag of $25 \mathrm{~kg}$

Pallets are used for handling the above-mentioned materials. Various problems need to be tackled while handling the pallets, are discussed in the forthcoming sections.

Manufacturing of each process mentioned above usually utilizes all or some of the above-mentioned raw materials. These raw materials are supplied from local and international markets. Further, different types of vehicles are used for its transportation and when arrived at the industry should be dealt in different manners to handle the product.

\section{FRAMEWORK IMPLEMENTATION}

The framework developed above is implemented at the case of Dynea Pakistan. The major steps discussed above are followed to improve the productivity.

\subsection{Existing Productivity Indicator:}

As discussed above, first of all the existing system of the selected process is analyzed and the factors influencing the productivity are identified and measured. In our case, the Molding Compound Powder (MCP) is selected for the study. Analysis of productivity measures results in the following problems:

\subsubsection{Lack of diversity in storage:}

Changing the product mix usually results in lack of storage space therefore there should be diversity in the storage media. In case of molding compound, different varieties are available, each have its own properties and should be stored and handled separately. The varieties of molding compound are represented as D140, D-150, D-250, V-170, V-180 and V-190. These different varieties are produced in different quantities depending upon demand for the respective type. Racks have been installed for the storage of these products but there is lack of diversity as the space is equally distributed to the different types of product while the demand is varied resulting in different quantities of product. In such a case the product having high demand and production faces the issue of less storage while there is extra storage available for the product having less demand and thus results in lack of space utilization.

\subsubsection{Fuel costs}

In our case the fuel charges play an important role in the total cost. Since most of the handling at warehouse is carried out through forklift trucks that's why it has a vital role in the efficiency and productivity. Most of the fuel is wasted in unnecessary travelling/ avoidable travelling. A proper plan is analyzed and discussed in the forthcoming sections.

\subsubsection{Honeycombing}

The major issue in our case is the parameters of the racks. Since the length and height of the racks has not been designed according to the parameters of pallets hence results in wastage of space but it is thoroughly discussed mathematically in the next section.

\subsubsection{Lacking in long term planning:}

Similar to the first problem we mentioned, not planning for changes in the business can easily chew up the profit margins. The future plans must be clear. Referring to our case, lack of proper planning is a major issue. New changes are introduced from time to time that not only increases the cost but also affects the productivity.

In existing process, a number of issues were identified which are discussed below. 
- Efficient delivery of the product is one of the major problems in an industry. Lack of proper material handling usually results in lower performance hence resulting in poor delivery performance. Delivery performance is ultimately related to the morale of the customer. On-time delivery improves the morale of the customer and increases the reputation the company. In our case, delivery performance could be considered as the availability of the required product at the required time with required quality to the customer. This problem exists when the raw materials are not provided at the required time and the finished product is delayed from the required time. Proper analysis has been provided in the next section.

- Buffer storages provide temporary storage. This storage usually occurs within the production lines. It could be assembly items or semi-finished goods. Buffer storages are very useful when one operation is dependent upon a prior operation. In case of malfunction, flow may remain constant if buffer storages are available. At each workstation, storage is available so that it can assist in critical situation. In our case, buffer storage is available at most of the sections that help in critical situations but it needs to be updated. Appropriate levels of buffer should be provided. Some of the sections are lacking in buffer storages that result in too many problems. Analysis and suggestions have been provided for such sections in the coming topics.

- Cost represents one of the major factors that must be analyzed accurately and should be dealt with great care. All of the above-mentioned problems are directly related to the operational costs. For example, in case of unavailability of buffer storage at the required time, production will be affected and hence results in loss. Similarly, inability to update the system with time to time may increases the unit cost of production. Data is collected for different operations and the associated costs have been analyzed and calculated in the section of Data collection and analysis.

- Quality is the parameter that represents the reputation of a company. Every customer requires quality but there must be a balance between quality and the cost of the quality as the cost increases sharply when the quality exceeds a specific limit. Quality is also directly related the company operations and procedures. It depends upon the equipment, machine and its user. Quality should be checked at each and every step so that the next section can measure its process and procedure. In our case, quality is checked at the end of the whole process that results in difficulty to find the error of low quality. Smoothness and cleanness represent quality parameters for the molding compound while viscosity is the major factor considered in the resin. Similarly, low curing and high flow are the desired quality parameters for glaze powder.

- Information flow represents the effectiveness of an organization. The smooth is the information flow the more is the organization effective. Information flows from one department to the other. Almost all the departments are interlinked directly or indirectly at any organization. At Dynea Pakistan, information flows among various organizations. The production reports are generated at the production plants and send to the production manager. There, a daily production report is prepared at online software. This software shares this data to the head office. Also, this information is shared with store department on the basis of which they can made dispatch orders to the customers. Similarly, quality department is responsible for approving or rejecting the lots on the basis of the sample. Information flow through software is smooth and is easily accessible. The problems exist in offline flow. Workers take the reports from each department and provide them to others. These problems are analyzed and discussed in next topics. Most of the man-hours are wasted in transferring files from one office to other. These hours could be saved and could be utilized efficiently if the flow was better. Other major problem is that most of the data is stored in hard files that result in difficulty to access on time or it may lose.

- Three main characteristics are considered while conducting ergonomics study. It is known as Ergonomic Stressors. It includes the force 
required to complete a task, any awkward or static working postures adopted in completing a task, and the repetitiveness of a task. Any of these factors, or any combination of these factors, may place someone at greater risk for discomfort. At Dynea Pakistan, issue of safety and ergonomics is very critical. There are no proper planning safety measures for the workers. Although the basic personal protective equipment is provided to each worker but the authority to implement safety is lacking in its responsibility. Further, lack of ergonomics is at its peak. The workers are working in very unsafe postures that could be dangerous to the health. Ergonomics is missing in each and every department of this industry. Each posture is discussed in the Solution section along with the recommended posture.

\subsection{Process material flow}

Fig. 2 depicts the complete process flow of molding compound powder at Dynea Pakistan. The process starts from syrup section where raw materials are added and mixed in the agitators. After processing time, it is transferred to kneader section where additional raw material s like cellulose and color pigments are added and is kneaded for a specific time of one hour. Further, it is transferred to dryer section where it is dried by passing through hot chambers of dryer. Finally, it is transferred to ball mills through dust collector and fine powder is received as the final product.

\section{ALTERNATE PROCESS MATERIAL HANDLING EQUIPMENT}

\subsection{Pallet Jack}

Pallets are used to support the material and unitize it. Urea bags, cellulose bundles and finished product bags are stacked on the pallets and then it is moved within or outside of the plant through pallet jacks. It is very useful for moving the load in short distance.

The problems associated with these pallet jacks include the lack of maintenance that results in too $\mathrm{h}$ difficulty. Other problem is that since the Molding compound being produced as the finished product gets sticky when it walked on by the people or by the movement of equipment so these this compound sticks to the wheels of the pallet jack and it provides difficulty for the worker to handle it and requires more force as compare to normal.

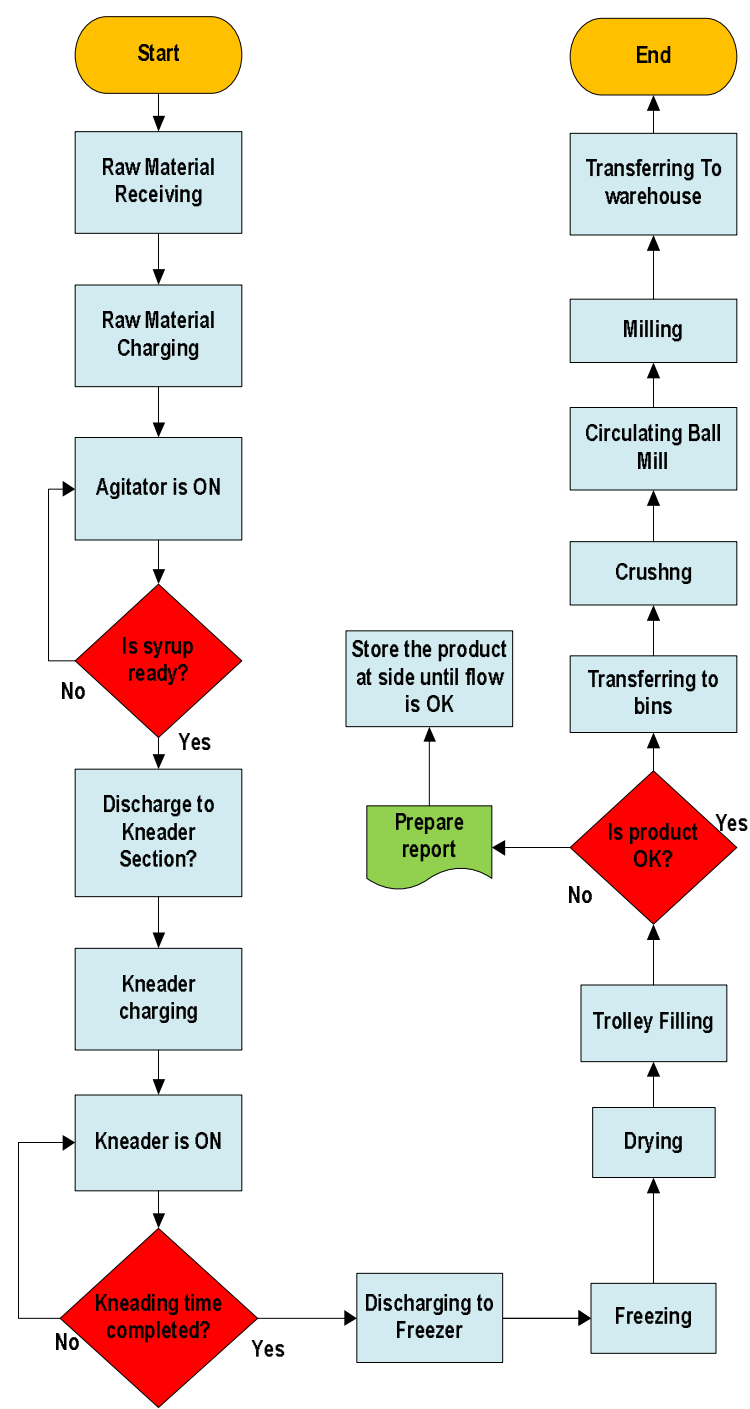

Fig. 2: Complete process flow of molding compound powder plant

\subsection{Storage Trolleys}

Storage trolleys (Fig. 3) works as a buffer storage in our process. The product being manufactures is temporarily stored in these trolleys and then shifted for further processing. These trolleys are used at two 
plants, Molding Compound and Glaze Plant. At both plants, the product from dryer is transferred to these trolleys through a mechanized screw conveyor. It is helpful in case if the product is not of the required quality so the respective trolley is isolated and hence saved the cost and time of further processing that is not worthy.

The problems associated with it are not too much serious but it would be better to improve it. First problem is the same as above that that the wheels get stuck with stick material and it becomes difficult to handle it. The other problem is that since the product continuously transfers to the trolley there must be a person to observe it and in case there is no observer, the product overflows the trolley.

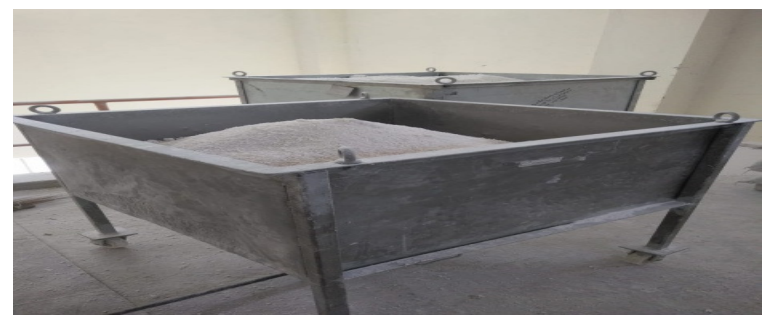

Fig. 3 Storage trolley

\subsection{Forklift Truck:}

Forklift trucks (Fig. 4) represent one the major material handling equipment in our case. It handles the pallets while transferring it from plant to plant or warehouse or within the plant. There are three forklift trucks available having different capacities. These trucks are also used to load and unload the vehicles.

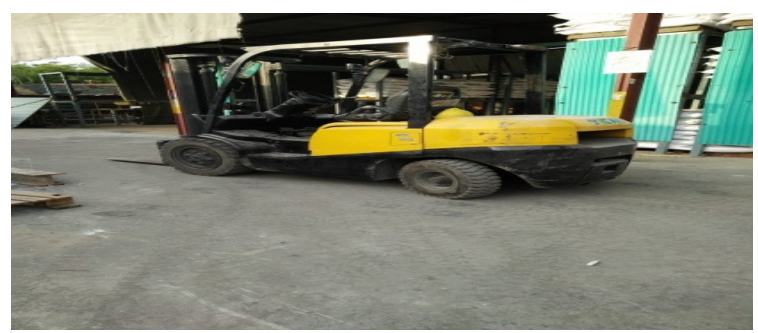

Fig. 4: Forklift Truck

Athough there is no major issues associated with these trucks but still there are some problems that need to be tackled. It includes the lack of preventive maintenance that results in often failures. There is no specific rules and regulations for the trucks and usually works in a very unsafe manner. Another problem related to safety and ergonomics is that there is no pathway defined for these trucks. Sometimes it is used for a load that is exceeding its limits and hence affecting its useful life.

\subsection{Hand Carts}

Hand carts are used to transfer the bags of returned product from one machine to other. It is similar to that of the pallet jacks. The pallet jacks move the unit loads while there is no unit load defined for transferring through it.

The problems associated with it are the same as the pallet jacks. Major problems include stickiness of material to the wheels and ergonomic problems of having the handle at a lower height.

\subsection{Hoist}

Hoists (Fig. 5) are used to move the heavy loads form one point to another point. There are seven hoists installed at our industry. The six hoists are used for lifting the load from one level to another level while the seventh hoist is used to lift the trolleys being filled at dust collector section and then transfer it from one place to another place. It moves along a straight rail and controlled from a remote. Push buttons are installed at the remote to move the load in the required direction.

There is no major problem associated with it. Some problems include lack of preventive maintenance that could delay the process in case of failures. There is no alternative source to these hoists and in case of failures, workers have to transfer the load manually that is a serious problem.

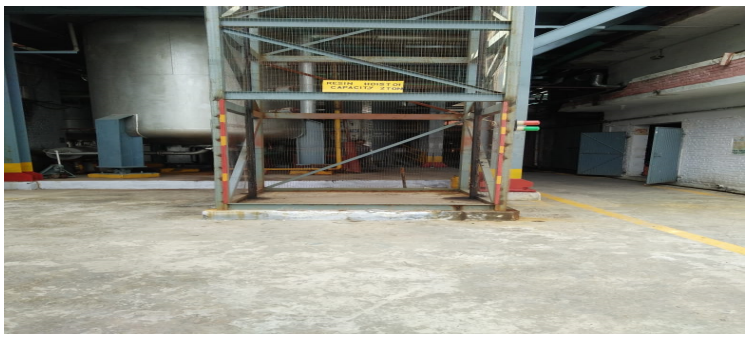

Fig. 5: Hoist

Mehran University Research Journal of Engineering and Technology, Vol. 40, No. 3, July 2021 [p-ISSN: 0254-7821, e-ISSN: 2413-7219] 


\subsection{Bins}

Bins shown in Fig. 6 are used at Glaze manufacturing plant. When the syrup is prepared, it is transferred to the bins and it then freezes out within these bins at the freezing room. A large number of bins are used to store this syrup. After freezing, these bins are transferred from the freezing room to slicing machine section where it is removed from the bins and then sliced through slicing machine.

The problems involved in this process include the handling of bins. These bins use too much space and as a result we cannot have more than five batches at a time as there is lack of space in the freezing room. Another problem is that there is no handle attached to the bins and hence it is difficult for workers to handle it. Similarly, while pouring the syrup into the bins, usually some quantity is wasted that could have been saved if managed properly. Another problem is the removal of frozen blocks from the bins. It has a good amount of weight and it is handled manually so there is ergonomics risks involved.

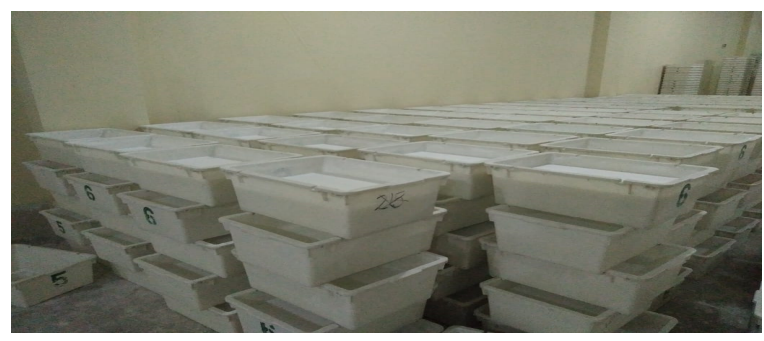

Fig. 6: Storage Bins

\subsection{Racks}

Racks are used to store the raw material and finished products. Most of the racks are allocated to the storage of finished products. The problems involved in the racks are its design problem. Each pallet has 35 bags of finished products that require a specific height while the height of rack is more than this required height and hence the space is wasted.

\subsection{Conveyor Belts}

These belts are installed at the dryers of each plant and are used to move the product along the dryer. It is a mechanized system and does not involve direct intervention of operators. There is no specific problem but in case of failures there is no alternative solutionand can impact the production and quality. Similarly, the preventive maintenance is somehow a major issue in this regard.

The above-mentioned tools and equipment are some of the major handling equipment that are used for handling the material at various stages. Although the handling is performed at each and every point of the whole process in one form or another but most of it is done manually and involves different ergonomics issues.

The data has been collected stepwise on the basis of operation being selected. Some of the problems do not require too much mathematical data but still they are discussed here. Most of the parameters related to the length are measured with the help of measuring tape, while the volumes are calculated by using respective formulas.

\subsection{Unit Load Design:}

Design of unit load play an important role in material handling design. MHE are selected on the basis of unit load design therefore its design should either be flexible or according to the MHE. In our case, unit load is designed at molding plant. Pallets are used to unitize the load. Each unit consists of 35 bags that are placed on the pallet in a specific manner in order to be easily handled. The data regarding pallet size are given as follows:

\section{Pallets $=2 \times 2.09=4.18$}

The racks are designed in such a way that a maximum of two pallets can be allocated to it. The parameters of each cell of the rack are given as follows:

Rack area $=4 \times 1.5=6$

Available area for the two pallets is $6 \mathrm{~m}^{2}$ while the area being occupied by the two pallets is $4.18 \mathrm{~m}^{2}$. Hence a total area of $1.82 \mathrm{~m}^{2}\left(6-4.18=1.82 \mathrm{~m}^{2}\right)$ could have been saved. However we are not discussing its solution here. A proposed design and solution will be provided in next sections.

After discussing the base area, let's have a look at the height of the rack and the height of the pallet being occupied by the bags. A layer of five bags is created On the pallet. Seven layers are created that form a lot of 35 bags (Unit Load). Approximately $5.5 \mathrm{ft}$ height 
is measured for each pallet that is equal to $1.67 \mathrm{~m}$. The height of each cell of rack is $7 \mathrm{ft}$ that is equal to $2.1 \mathrm{~m}$. Hence it results in loss of $0.46 \mathrm{~m}(2.1-1.67)$. It represents a large amount of space that is wasted. It could have been utilized if managed properly. A suitable suggestion would be provided in the next section.

Space utilized by the pallets $=4.18 \times 1.67=$ 6.9 cubic meter

Space avaiable for two pallets $=6 \times 2.1=$ 12.6 cubic meter

\subsection{Storage Space Utilization:}

For our case, the storage space utilization has been calculated for unit rack.

$\mathrm{SSU}=\frac{6.9}{12.6}=0.54=54 \%$

\subsection{Bins Design Parameters and Efficiency}

Similar to unit design, bins design also play an important role. The efficiency of bin is dependent upon its size and level of fill. The size should be an optimum so that it can be handled easily.

In our case, bins are used to store glaze syrup. Their parameters are given as follows:

Area of the bin $=0.36 \times 0.28=0.10$ square meter Available space $=0.25 \times 0.10=0.025$ cubic meter Usable space $=0.21 \times 0.10=0.021$ cubic meter Hence,

Container Space Utilization $=\frac{0.021}{0.025}=84 \%$
Nesting Ratio $=\frac{0.25}{0.22}=1.13$

\subsection{Material Handling and Labor Ratio:}

Here we are going to calculate it for only milling sction.

Pesonnel assigned to $\mathrm{MH}=4$

Total workers $=5 \mathrm{MHL}=\frac{4}{5}=0.80$

\subsection{Handling Equipment Utilization Ratio:}

It is also calculated for only milling section as the production is directly associated with this section. On the basis of unit bag production, theoretically one ball mill can produce 130 bags while usually the actual number of bags varies.

No. of Bags moved per hour $=35$

Theoretical No. of bags to be moved $=65$

$\mathrm{HEP}=\frac{35}{65}=0.54$

\subsection{Manufacturing Cycle Efficiency:}

In computing for the manufacturing cycle efficiency, the time spent for value added activities is compared to the entire manufacturing cycle time. The manufacturing cycle time includes process time, inspection time, move time, and queue time (See Table 1). Process time refers to the length of time spent in working on the products.

From Table 1:

\begin{tabular}{|c|c|c|c|c|c|}
\hline \multicolumn{6}{|c|}{ Table 1: Process recording sheet for molding compound powder } \\
\hline \multicolumn{4}{|c|}{ Process Recording Sheet } & Page\# & \\
\hline $\begin{array}{c}\text { Process } \\
\text { Observed }\end{array}$ & & & \multicolumn{3}{|c|}{ Observer } \\
\hline Start Point & \multicolumn{2}{|c|}{ Syrup section } & \multicolumn{3}{|c|}{ Observation Date } \\
\hline End Point & Total Cycle Time & $14 \mathrm{hr}$ & & & \\
\hline Step\# & Step Description & Worker's Name & Start Time & End Time & Cycle Time \\
\hline 1 & Raw material Charging & A & 7:00 AM & $7: 15$ AM & 15 \\
\hline 2 & Syrup Preparation & $\mathrm{B}$ & $7: 16 \mathrm{AM}$ & $8: 40 \mathrm{AM}$ & 85 \\
\hline 3 & Kneader Charging & $\mathrm{C}$ & $8: 41 \mathrm{AM}$ & $8: 55 \mathrm{AM}$ & 15 \\
\hline 4 & Kneading & $\mathrm{D}$ & $8: 56 \mathrm{AM}$ & $9: 56$ AM & 60 \\
\hline 5 & Kneader Discharging & $\mathrm{E}$ & $9: 57 \mathrm{AM}$ & $10: 12 \mathrm{AM}$ & 15 \\
\hline 6 & Freezing & $\mathrm{F}$ & 10:13 AM & $10: 58 \mathrm{AM}$ & 45 \\
\hline
\end{tabular}


Manufacturing Cycle Efiiciency $=\frac{290}{470}=62 \%$

\subsection{MH Equipment-Operating Cost per Unit Distance:}

Productivity Ratios are used as indicators of the Performance of a system. These ratios are monitored periodically to be sure that their values are within acceptable tolerances.

MH equipment costs usually involve the cost of fuel and maintenance of the equipment. Although the initial cost of the equipment to purchase and install is also a factor but that is usually recovered within its life time.

In our case, the basic cost of $\mathrm{MH}$ is the cost of fuel used by forklift trucks, that are used for moving the unit loads from one place to another, electric cost that is consumed by the hoists' motors and conveyor belts. We use forklifts almost all the time during working hours. Forklifts are available for use for 15 hours a day. There are three forklift trucks and a total of six operators, 2 for each with 530 per day wages. Average fuel cost calculated for each forklift is obtained as 380 rupees per hour. Average maintenance cost results in 75 rupees per hour. Distance measured on average scale is $1050 \mathrm{~m} / \mathrm{hr}$.

Hence the total cost of one forklift per hour can be calculated as follows:

Forklift cost per hour $=\frac{\text { Total cost per hr }}{\text { distance travelled per } \mathrm{hr}}=$

$\frac{380+9.375+66.25}{1050}=\frac{0.43}{\mathrm{~m}}$

Similarly, each hoist is run by a motor of $2.2 \mathrm{KW}$ that requires an average of 4 Ampere to operate. There are a total seven hoist that uses the electricity in such amount. Although proper and complete analysis of hoist and conveyor belts have not been done as it has to deal with loads and if the motor is reduced then it will result in failure of the motor.

Additionally, other material handling equipment do not use any form of energy and are associated with workers. They also have initial costs but most of these have completed their useful life and considering its initial cost would not matter.

\section{NEW CASE PRODUCTIVITY INDICATORS}

All the procedures and the methods have been explained thoroughly in the above sections. Data for each parameter were collected and analyzed. All the problems involved were identified and measured. Now to solve these problems, designs and methods will be provided with proper planning and then it will be implemented.

\subsection{Planning and Design Phase:}

Analyzing all the problems being faced must now be tackled thoroughly. To do so, a proper planning should be done so that the study and struggle results in an optimized manner and provide fruitful solutions to the organization for its betterment and improvement.

Now considering each problem, a solution will be provided with specific and feasible design features. The solutions to the problems are provided as follows:

\subsection{Storage Space Utilization and Unit load Design:}

Since there is enough amount of space wasted in the racks and could have been saved. To save it, we have two options: either adjust the racks design and parameters according to the unit load or adjust unit load according to the racks.

Adjusting racks is not an easy task and will be wastage of time and money however we can change the unit load design that will utilize more space in the racks.

Unit load is updated to have three more layers of bags i.e. a total of fifty bags on each pallet will be our unit load. It will cover up the space being wasted and save the space occupied.

Hence the SSU is given as:

$\mathrm{SSU}=\frac{9.5}{12}=0.80=80 \%$

The efficiency could have been improved more but some space is left in order to handle properly and easily. The SSU improved from $54 \%$ to $80 \%$. It is quite 
a great achievement to optimize the system at such level. Horizontal space could have also been saved by changing the pallet parameters but replacing all the old pallets with new ones does not seem economical and it is better to have these ones. However in case there are new pallets required then that must be according to the racks parameters.

\subsection{Bins Efficiency Improvement}

In case of bins, we are not going to change the design as it will also require the replacement of old bins. We'll change only one parameter and that is the height of the product inside the bin. As a result there will be less number of bins required and less space will be utilized by the bins. The improved container space utilization can be found as:

Improved Container Space Utilization $=\frac{0.23}{0.25}$

$$
=0.92=92 \%
$$

Similarly the new Nesting ration is given as:

Improved Nesting Ratio $=\frac{0.25}{0.23}=1.08$

Hence the container space utilization is improved from $84 \%$ to $92 \%$.

\subsection{Material Handling/ Labor Ratio}

Currently the product is handled by four of the five workers as explained earlier. Now the scaling worker will be responsible for sewing also as a result one worker will get rest at a time and will be available for any other task required urgently. With three persons assigned to material handling, new material handling labor ratio is calculated as follows;

$\mathrm{MHL}=\frac{3}{5}=0.6$

\subsection{Handling Equipment Utilization Ratio}

Since the unit load design has been changed and the number of bags in each unit of load now has 50 bags therefore fifty bags could be handled in an hour by changing other parameters. New data can be given as follows:

$\mathrm{HEP}=\frac{50}{65}=0.77$

\subsection{Manufacturing Cycle Efficiency}

MCE can be improved if the workers are utilized in milling while crushing is carried out on other side. In this scenario, the crushing time can be saved and made productive. After eliminating crushing time, the data is updated as follows:

Manufacturing Cycle Efiiciency $=\frac{290}{390}=0.74=$ $74 \%$

\subsection{Forklift Truck Cost per Hour:}

Forklift cost can only be reduced in two cases:

- Reduce less quantity of fuel

- Travels less distance

The first case can only be possible if we replace the current forklift with a more efficient and new forklift and it is a very tough decision to take therefore it is neglected.

In second option, efficiency can be increased if the forklift travels less distance and it can be possible. Currently we are having three forklifts and they are used for multi purposes i.e. loading/unloading, raw material and finished products transfer of all the plants. So if we assign each forklift to two plants and one forklift to loading/unloading, the distance can be reduced as the unnecessary travelling will be finished and will have a specific tasks to do. As a result much distance could be travelled in less time. Data is given as follows:

The cost per hour can now be calculated as:

Forklift cost per hour $=\frac{\text { Total cost per } \mathrm{hr}}{\text { distance travelled per hr }}=$ $\frac{380+9.375+66.25}{1320}=\frac{0.34}{\mathrm{~m}}$

\section{DISCUSSIONS}

In this paper, a research framework for analyzing stems efficiency in terms of material handling systems design and ergonomics, is developed. The framework provides a general methodology that can be used for studying any process and find the loopholes. Referring to the framework, a case study is discussed where the framework is used to identify the major factors contributing to poor efficiency. Material handling 
system and ergonomics are considered for detailed study.

Previous literature studies different procedures and have developed a number of techniques to select suitable MHE but there are very few research papers available that have considered the improvement of existing MHE. Since adopting a new MH system requires a large amount of investment which is not always feasible for small and medium firms therefore this paper discusses a framework that provides guidance to improve the existing system. The framework is explained with the help of a case study.

\section{CONCLUSION}

Material handling plays a crucial role in the development of an organization. About $70 \%$ of the cost and time is utilized in handling the materials therefore it needs a proper discussion. In our case, the basic elements and parameters were discussed and analyzed thoroughly. New methods were suggested and then the parameters and efficiencies were recalculated to find the difference between current and improved system. The results achieved are discussed as follows:

- Storage Space Utilization: SSU is improved from $54 \%$ to $80 \%$

- Container Space Utilization: It has improved from $84 \%$ to $92 \%$

- Nested Ratio: It reduced from 1.19 to 1.08

- Material Handling Labor Ratio: It reduced from 0.8 to 0.6

- Handling Equipment Utilization Ratio: It improved from 0.54 to 0.77

- Manufacturing Cycle Efficiency: It improved from $62 \%$ to $74 \%$

- Forklift Cost per Distance: Cost reduced from RS0.43/m to $0.34 / \mathrm{m}$

These parameters could have been improved more but it would cost too much as some of the equipment need to be changed and replaced with new one. If this study was conducted before purchasing of material handling equipment, we could save enough money. Still it is a great achievement to improve the system without costing much.

\section{FUTURE RECOMMENDATIONS}

DYNEA Pakistan Company can gain from this study if they act on the following recommendations,

- the production facility should change the vibrator's type to reduce the powder waste,

- the company must employ Push pull interface,

- reduce their raw material inventory by placing an order on a specific time period.

We have not simulated the model, so future research could focus on the simulation of the production process. Simulation can help in visualizing the effects of the changes made in the layout and process methodologies. It also helps in cost savings and reducing the risk of failure as it just requires accurate data to generate results. Simulation can further improve the process by consideration of the factors and facilities that cannot not be induced in real systems easily. Additionally, analyze the methods to reduce raw material inventory and develop models to reduce the transportation time between the plant and warehouse, etc. Repeat studies on other models of the same process in order to enhance the reliability of the findings would be beneficial.

\section{REFERENCES}

1. Tompkins J.A., White J.A., Bozer Y.A., Tanchoco J.M.A., "Facilities planning", John Wiley and Sons. 2010.

2. Chhajed D., Montreuil B., Lowe T.J., "Flow network design formanufacturing systems layout", European Journal of Operational Research, Vol. 57, No. 2, pp. 145-161. 1992.

3. IKarwowski W., The Discipline of ergonomics and Human Factors", John Wiley \& Sons, 2006.

4. Felten, D.F., "Performance by design: Sociotechnical systems in North America", Prentice Hall, 1993.

5. Schmidt K., Bannon L., "Taking CSCW Seriosly: Supporting Articulation Work", Computer Supported Cooperative Work, pp. 7-40, 1992. 
6. Mital A., "Manual versus flexible assembly: a cross comparison of performance and cost in four different countries", In Parsaei S.R., Mital A. (Eds.), Economic Aspects of Advanced Production and Manufacturing, Chapman \& Hall, London, 1991.

7. Jenkins S., Rickards J., "The economics of ergonomics: three workplace design case studies", Applied ergonomics, pp. 251-256, CRC Press. 2001.

8. Welgama P., Gibson P., "An integrated methodology for automating the determination of layout and materials handling system", International Journal of Production Research, Vol. 34, No. 8, pp. 2247-2264, 1996.

9. Mohsen, Hassan M.D., "A framework for selection of material handling equipment in manufacturing and logistics facilities", Journal of Manufacturing Technology Management, Vol. 21, No. 2, pp. 246-268, 2010.

10. Webster D.B., Reed JR. R., "A material handling system selection model", AIIE Transactions, Vol. 2, No.1, pp. 1-21, 1971.

11. Palliyil G., Goetschalckx M., "A comprehensive model for the concurrent determination of aisles and load stations for aisle-based material handling systems", Technical Report, Georgia Institute of Technology, 1994.

12. Don T.G., English J.R., Graves R.J., "Designing new products: compatibility with existing production facilities and anticipated product mix", Integrated Manufacturing Systems, Vol. 5, No. 4/5, pp. 13-21, 1994.
13. Dowlatshahi S.A., "Modelling approach to design of integrated facilities", The International Journal of Production Research, Vol. 32, No. 6, pp. 13131330, 1994.

14. Peters A., Yang S., Chisowa E., "Monoazo disperse dyes derived from nitro-2aminobenzothiazoles", Dyes and Pigments, Vol. 28, No.3, pp. 151-164, 1995.

15. Askin R.G., Mitwasi M.G., "Integrating facility layout with process selection and capacity planning", European Journal of Operational Research, Vol. 57, No. 2, pp. 162-173, 1992.

16. Park Y.-B., "ICMESE: intelligent consultant system for material handling equipment selection and evaluation",. Journal of Manufacturing Systems, Vol. 15, No. 5, pp. 325-333, 1996.

17. Glah B., Banyal T., Cselenyl J., "Comparison of direct and indirect distribution of a network-like operating logistics integrated assembly system", Production Systems and Information Engineering, Vol. 4, pp. 125-145, 2006.

18. Cselényi J., Illés B., Logistics Systems", University of Miskolc: Miskolc, Hungary, 2004.

19. Cselényi J., Illés B., "Planning and Controlling of Material Flow Systems", Miskolci Egyetemi Kiadó, 2006.

20. Bányai T., "Structured Modelling of Integrated Material Flow Systems, GÉP, 2012. 